The Park itself has unique ecosystems and wider ecocomplexes which compromise the 'Shivalik Ranges', formed by the 'debris washed down from the Himalayas' millions of years ago. It supports at least 25 mammal species and 315 species of birds.

Geologically the Shivaliks are fragile, consisting of boulders and conglomerates of variegated clay together with coarse-grained coloured sandstone and brown shale. This weak constitution is vulnerable to erosion. Being forested, however, the tree cover mainly of Sal (Shorea robusta) has so far been able to staunch the flow of rainwater, reducing runoffs and erosion. During the monsoons, the streams that remain dry for most of the year are converted to raging torrents carrying huge boulders and trees downstream. When the rain subsides, the streams revert to their bone-dry appearance almost within hours, leaving only scattered traces of water.

The inescapable compulsion due to human necessity has now opened up the forest canopy, encouraging rainwater to wash the topsoil from the hills, along with boulders and rubble which find their way to flat stream-beds called 'raos'.

Adding further to these conditions, with indiscriminate lopping and felling of trees, a downward spiral of action has resulted in staving off regeneration and seeding. Thus, sunlight filtering through the open canopy has encouraged weed growth, so that $40 \%$ of the ground cover is now choked with lantana, parthenium, Cannabis sativa, and Cassia tora.

Because of the lack of ground-cover, much of the natural flora has died and Elephants are unable to find sufficient food-source. With herd numbers rising alarmingly in these reduced habitats and scarce food-sources, the Elephants have no alternative but to invade cultivated

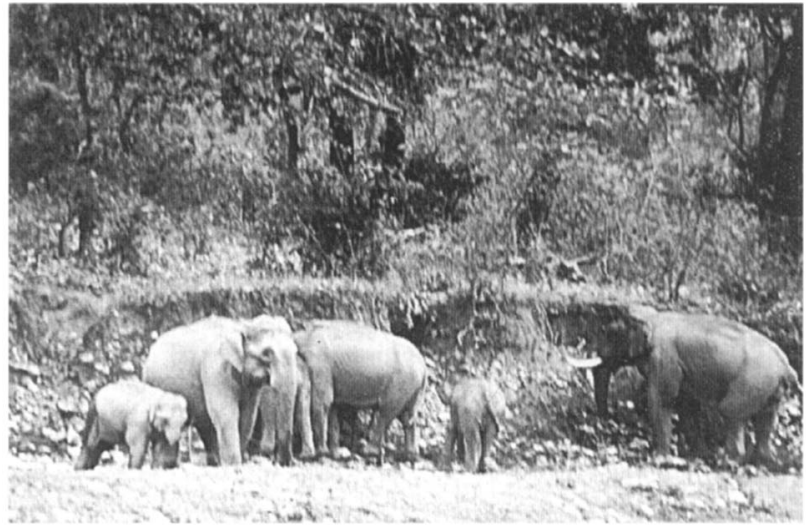

FIG. 1. A herd of Elephants in the Rajaji National Park.

fields outside the Park, which results in increased incidents of human causualties caused by Elephants in search of food.

Now, the very survival of the Elephants is at stake, these being the last forests in Northwest India where Elephants still reside. But with the flood-tide of human encroachment, if nothing is done soon, they will eventually, and most regrettably, vanish from them and foreseeably for ever.

Keshab N. Chowdhury, Coordinator Center for Elephant Studies

2 Laxmi Road

Dalanwala

Dehra Dun 248001

$U P$, India.

\title{
OECD Review of Rural Policy in Switzerland
}

$\mathrm{T}_{\mathrm{s}}^{\mathrm{s}}$ he OECD (Organization for Economic Cooperation \& Development) Group of the Council on Rural Development reviewed rural policy in Switzerland in the course of its meeting in Paris from 7th to 9th December 1994. After Finland, this was the second review by the OECD of the rural policy of a Member country.

Switzerland is densely populated in comparison with most OECD Member countries, but $40 \%$ of its population still lives on the more than $80 \%$ of its territory which is described as rural. Moreover, rural areas make a significant contribution to the national economy and not merely to Switzerland's image in the world.

As part of its government's programme for the period ending in 1995, the Swiss Federal Council has set the goal of reorienting its current regional policy. One result of the cooperative efforts of the federal offices concerned with the new orientation of regional policy has been the development of a draft Action Programme to Overcome Structural Changes and Promote Cooperation in Rural Areas. The design of the draft programme was carried out with the support of the Advisory Commission to the Federal Council on Regional Policy.

From the outset, Switzerland collaborated actively with the OECD, which has been addressing this issue for several years. Thus, the Organization was invited by the Swiss authorities to carry out an 'ex-ante' review of the REGIOPlus Programme before its submission to the Swiss decisionmakers for approval. In that context, OECD experts also carried out on-the-spot studies of the current structures and forthcoming challenges in various rural area of the Jura, the Plains, and the Alps.
In view of the coming structural adjustment in the agricultural sector (agricultural policy reform and the GATT Agreement), and of the industrial and services sectors' tendency towards spatial concentration, the development of Switzerland's rural areas requires, as in other OECD countries, appropriate structural measures to be taken by the federal authorities.

The problems and challenges of rural development must, by their nature, be dealt with locally, but consideration must also be given to their regional context as well as to the growing integration of rural areas into the national and international economy. These issues must also be addressed in the light of the major spatial impact of many of the sectoral policies that are introduced by the federal authorities.

The draft 'REGIO-Plus Programme' is aimed at helping to resolve these issues. By design a multidisciplinary, market-driven incentive programme, its goal is to help rural areas to adapt to structural adjustment by promoting and turning to account their economic and socio-cultural diversity and multifunctionality.

By promoting the implementation of innovative, exemplary and economically-viable projects, the establishment of new kinds of partnerships and institutional arrangements and, finally, the enhancement of Switzerland's rich natural and Man-made heritage, REGIO-Plus gives rural policy sufficient scope to deal with changing conditions in Switzerland and in the world. As one of a series of similar initiatives taken by other OECD Member countries, it is of international importance. 
In conclusion, the OECD considers the expected implementation of the REGIO-Plus Programme to be an appropriate and necessary addition to Switzerland's present array of regional policy tools. It should be a means of answering the challenges facing rural communities while at the same time fulfilling the expectations of society as a whole where rural areas are concerned.
Christian HuIllet, Acting Head Rural Development Programme $O E C D$

2 Rue André-Pascal 75775 Paris Cedex 16 France.

\section{Wetlands of Uruguay Threatened Again by Inappropriate Development}

$\mathrm{H}$ eedless development of two sorts threatens the survival of the Rocha coastal wetlands, which are said to be the second largest in the Americas after the Florida Everglades. The Uruguayan Department of Rocha lies immediately south of the southernmost end of the coast of Brazil, the border town of Chui being $340 \mathrm{~km}$ ENE of Montevideo. Prominent among Rocha's topographical features were four big freshwater lagoons that opened occasionally to the sea after heavy storms. Bordering these lagoons were some half-million hectares of wetlands that were recognized by 150 signatory countries to the 1982 Ramsar Convention as being of critical international importance.*

Six years earlier, Uruguay had formally accepted inclusion of these wetlands in UNESCO's Man and the Biosphere (MAB) Programme. Uruguay is a signatory to the Washington Convention of 1969 for the protection of fauna and flora and areas of especial natural scenic importance, and also to the Bonn Convention of 1989 for the conservation of migratory species of wild animals. Uruguay strongly supported the Rio Declaration of 1992, one of four main thrusts of the UN Conference on the Environment and Development being the safeguarding of biodiversity.

Wetlands are now recognized as being among the richest in species diversity of all fish and wildlife habitats. The wetlands of Rocha, or Banados del Este as they are called locally, support a great diversity of flora and fauna, including at least 120 species of waterbirds, 80 of fish, and 30 of amphibians. They are believed to be vital to the winter migrations of a dozen species of Arctic birds and a much larger number of Antarctic species.

Rationalizing that the wetlands of Rocha are one of the most environmentally diverse natural habitats in the world, as well as one of the least known, the Global Environment Facility (a financial 'window' of the World Bank) is funding a United Nations Development Programme project to assist Uruguay to construct and operate a wetlands research institute in Rocha.

\section{Road Construction Threat to Lagoon}

Seeking to serve the developers of tourist facilities and beach homes as they expand rapidly eastwards from Punta Del Este, the Government of Uruguay has announced its intention to shorten the distance to La Paloma by constructing a causeway joining the two arms of the Rocha

* Ramsar is the name of a town in Iran which, under prompting by Dr Eskandar Firouz, agreed to host an IUCN (International Union for Conservation of Nature and Natural Resources, now named the World Conservation Union) conference on migratory bird species' survival.
Lagoon. This would allow the sea to have tidal access into the Lagoon and its freshwater values would be forever lost, repeating stupefyingly what happened under similar circumstances to Garzon Lagoon only a few years ago. Since Laguna Negra is drying out as a consequence of the introduction of rice-growing, there would then be left only Laguna de Castillos as the last of the freshwater lagoons in the country.

\section{Rice-growing Again Threatens More Wetlands}

Making use of the wetlands water in Rocha for ricegrowing was started in the late 1970 s by a consortium of large companies and banks at an unusual time in Uruguay, when the country was under a military junta and starved of foreign exchange. Ten years on, the companies involved began to understand from declining yields that they would do better to move to less low-lying lands. A dam in the middle of Rocha having the capacity to irrigate 10,000 hectares is being used for only one-third of that amount, as I saw last November from the window of a small aeroplane belonging to one of the rice-growing companies. The ecological cost has been the loss of more than a quarter of the wetlands.

During the course of several conversations with Dr Enrique Zunini Fernandez, a veterinarian and President of the Comision de Flora Y Fauna, Sociedad Ecologica Rochiense, I learned that the Government has plans, already approved by Assembly decree, to canalize yet more water in the wetlands. One scheme, that is masquerading as a public benefit, is for diverting drainage water from polluting a beach by lifting it away into Lake Mirim, most of which lies in Brazil. The above-mentioned Dr Zunini has written a paper stressing the absurdity of official persistence in promoting investment-intensive, mechanized rice-growing in areas that have already proved to be unsuitable for viable commercial rice production.

In Environmental Conservation's 1994 Spring issue, there appeared a Note heralding the establishment of a Secretariat for the Ramsar Convention in Gland, Switzerland. Hopefully, it will have received a copy of Dr Zunini's paper and gone into action to arouse attention to the possibility that Uruguay may be about to disregard quite flagrantly its responsibilities for the safeguarding of the wetlands of Rocha.

PHILIP B. THRESHER
Juan Crespi Lane
Santa Barbara
California $93150-0018$
USA.

PHILIP B. THRESHER USA

\section{Advances in Ecology for Population and Community Specialists}

$\mathrm{O}$ ne of the most exciting current developments in population and community. ecology is the increasing integration of theoretical and empirical studies. This is eroding the barriers between the largely separate traditions of theoretical, experimental, and field, ecology which have developed through much of this century. These advances are happening at an opportune time in that there is an urgent need for a more analytical understanding of the dynamics of natural systems - to lessen the impact of human activities, to sustain renewable resources, and to exploit the 